\title{
A Caribbean experience
}

I am not the first to write of their sabbatical experience in the West Indies. ${ }^{1}$ So why write another? Each experience is unique and not sharing mine would be a missed opportunity for others to see its huge potential.

\section{PREPARATION AND PLANNING}

This started over a year in advance. I looked into the possibility of extended study-leave funding. However, since the GP contract of 2004, funding is at the discretion of the PCT.2

A locum already known to the practice was secured; handover was seamless. Relevant personnel were informed, notably the local trust, defence union, and of course, my patients. Time with the accountant was invaluable. Many subscriptions can be suspended, which is a financial saving and avoids polevaulting over a mountain of journals on return. With computer access, e-learning has made keeping up-to-date possible.

With an educational background and holder of a Certificate in Medical Education, I looked into teaching abroad. Some excellent universities were keen to offer me work without financial support. Although a salary was low on my list of priorities, I would at least try to avoid severe fiscal injury.

In order to enhance my teaching skills, I completed a course in Teaching English as a Foreign Language (TEFL).

I accessed the WHO's list of medical schools and was surprised to note that there are a number of international schools listed in the West Indies. It was at one such school that I spent a fascinating 6 months teaching undergraduates clinical medicine.

\section{AN UNCONVENTIONAL INTERVIEW}

I accessed The American University of Antigua's website, completed the online application, attached my CV and personal statement and thought little more of it until I received a call from the chair of the department of clinical medicine. This was quickly followed by a telephone interview by the dean. Within days I received my contract which also included a fullyserviced house on the waters' edge and return tickets. It was only later I discovered that the area had previously been known as 'Mosquito Cove'! Even considering the expense of insect repellents and antihistamines, it was a small price to pay for such an idyllic setting.

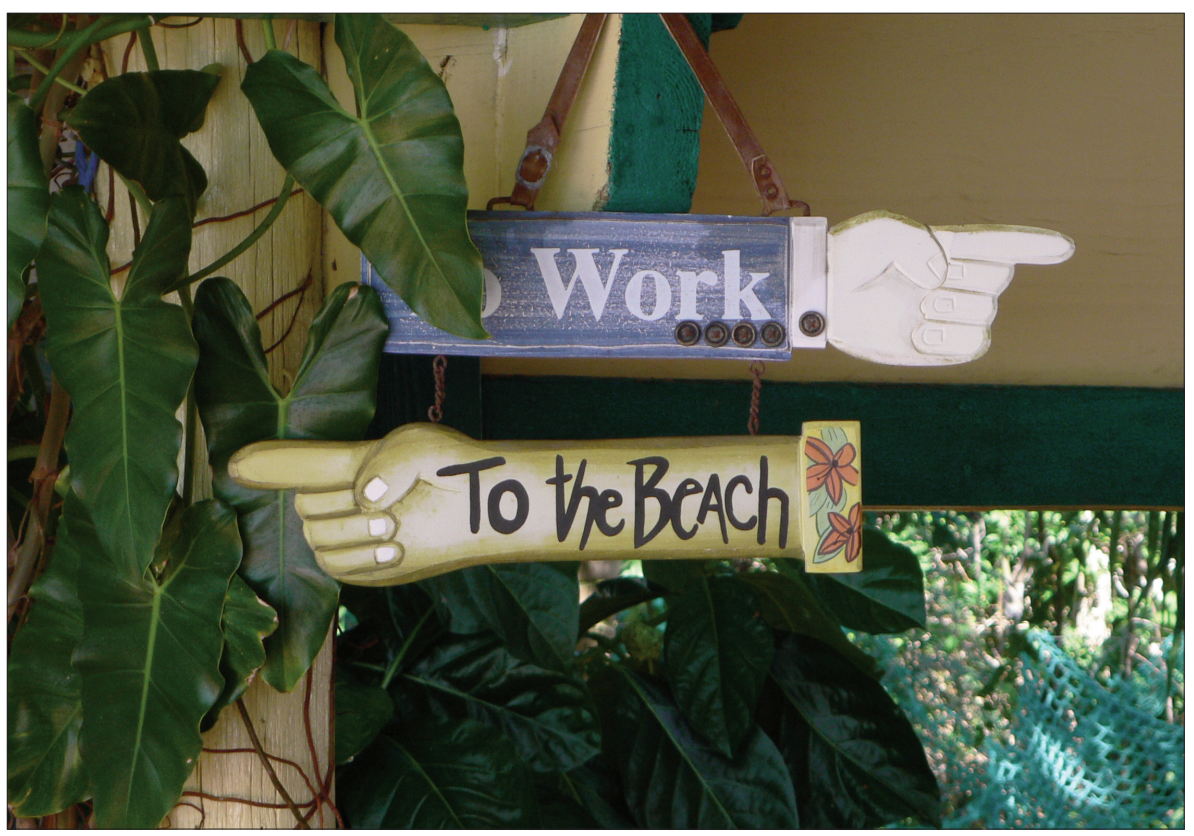

\section{DEPARTURES AND ARRIVALS}

Travelling to Gatwick airport felt very familiar but also quite surreal when I reminded myself that this was not a journey to start a 2 week holiday. We were met at Antigua's airport by a faculty member and driver. Introducing my husband, who after the long journey sported a red wine-stained shirt and a hair-do Bart Simpson would be proud of, was a good ice-breaker. The journey to our rented house seemed never-ending, arriving in the dark with all its unfamiliarity.

This was a journey I was to repeat, hundreds of times over the next 6 months in a battered old car, which I suspect had previously had at least 50 owners! A journey I never tired of despite having to dodge massive pot-holes, negotiate donkeys, goats, cockerels and stray dogs, not to mention school children in their pretty uniforms and women carrying their heavy head-loads. Friday night posed additional challenges as this was when local communities met at road-side barbecues which invariably spilled over into road parties. It was also a popular day for funerals, which in Antigua are seen as a celebration of life. The funeral cortege also stopped traffic, perhaps something to do with there being more stilettos and diamante on display than on 'Strictly Come Dancing'.

\section{BAPTISM BY FIRE}

I arrived at work the next morning and after a brief tour of the campus was shown to my office. Most of my colleagues had not yet returned to work after the summer break. I felt somewhat at sea but decided to just get on with it and start my teaching preparation. I remembered wistfully the hours I had spent, over the years, on organising a 2 week induction-period for our practice registrars.

This was the rainy season, where although temperatures varied by only 4 degrees $\left(28-32^{\circ} \mathrm{C}\right)$, the humidity was constantly high. Air-conditioning often didn't work either at home or at work. This 
made a severe menopausal flush seem like a walk in the park. Notwithstanding this, I did not need reminding that I was missing a British winter.

Within 2 weeks of my arrival we were at full complement. Although good for morale and companionship, sharing an office with two colleagues, one of whom given to thinking out loud, in an ambient temperature of $32^{\circ} \mathrm{C}$, gives a new dimension to hot-desking!

\section{THE CHALLENGES}

Teaching international students was an exciting new challenge. For many students this was their first experience away from home in a very different culture and climate.

I was responsible for teaching both first and fourth semester students clinical medicine. This entailed the syllabus of Doctor/Patient/Society and Introduction to Clinical Medicine in lecture and small group format as well as patient-based clinical skills teaching. This was integrated systems-based teaching with some hospital visits. It was a heavy teaching commitment to over 450 students. The first few months I was preparing and practising teaching material in my sleep. Insomnia was never a problem. However, teaching space was, with some lectures starting at $7 \mathrm{am}$.

Every lecture room had a slightly different idiosyncratic IT system which needed to be accounted for. Leaving the house shortly before 6am, became a routine which was no sacrifice when I could witness the sky come to life with blazing light and 3D cloud formation. My car radio was a great companion, in particular a phone-in programme, where the host mediated between quarrelling community residents. If only British general practice was that easy!

The patients were a delight and a joy to work with, more than happy to give up their time to benefit students, most of whom would not be serving the local community as qualified doctors. They were always ready with a beaming smile and infectious laugh. I taught or examined on conditions which although common, are seen less frequently in the UK, for example: young hypertensives, young CVAs, Graves disease, aortic regurgitation with textbook water-hammer pulse and cleft palate, to name but a few.

\section{WHAT HAVE I LEARNT?}

What it is like to live and work in a developing country; patience, flexibility and tolerance really are virtues. I learnt wisdom from some senior colleagues and an appreciation that some things can be completed at glacial pace without jeopardy.

It was fascinating working with international colleagues of varied backgrounds and experiences. I learned from them something of the health systems in other countries. It made me appreciate even more our NHS, a system I have worked in for over 22 years.

I learnt some pretty useful skills in those first few weeks, which included how to continue teaching through a power cut. However familiar this was and good at improvisation I became, it was always going to be a challenge without light! It certainly taught me the importance of having at least a mental lesson plan. I honed my own clinical examination skills and revised many systems diseases. I was asked to organise and help run a clinical skills examination, produce a professionalism charter and write a clinical skills work book for fourth semester students. This work book continues to be used by current students. I made some friends and was allowed for a few months to take a different perspective on life. I also learnt a lot about myself.

\section{THE FUTURE}

I have read that your time out 'may have triggered a realisation that changes are needed in your career or personal life'. ${ }^{3}$ Well not yet, but it's certainly fuelled my enthusiasm for teaching. I plan to embrace the challenges of returning to general practice and hope the transition will be as smooth as possible; a place where changes are guaranteed but never at glacial pace.

\section{Gwawr J David}

\section{REFERENCES}

1. Oliver J. My three month sabbatical in Jamaica. Pulse 16 Nov 2007.

http://www.pulsetoday.co.uk/story.asp?sectioncode=2 2\&storycode $=4115922$ (accessed 13 May 2008).

2. Kemple T. Taking a sabbatical in general practice. BMJ 1998; 316(7127): 24 Jan.

http://bmj.bmjjournals.com/cgi/content/full/316/712 7/S2-7127?ck=nck (accessed 9 May 2008).

3. Chok S. Sabbaticals in general practice. BMJ Careers 2005; doi:10.1136/bmj.330.7501.sgp210.

http://careers.bmi.com/careers/advice/viewarticle.html?id=865 (accessed 13 May 2008).

DOI: 10.3399/bjgp08X302844 